\title{
Práticas de controle social na percepção do poder executivo: um estudo dos entes federativos brasileiros
}

\section{Social control practices in the perception of the state executive: a case of the entities in brazilian states and the federal district}

\author{
Fábio Ferreira da Silva ${ }^{1}$ \\ Haroldo Cristovam Teixeira Leite ${ }^{2}$
}

\section{Resumo}

O presente estudo tem como objetivo identificar a existência das práticas de controle social na percepção dos representantes do controle interno do poder executivo estadual, verificando se as disponibilizações de tais práticas possuem associação com a governança pública. A pesquisa é de natureza aplicada, quantitativa e, quanto aos objetivos, descritiva. A população compreende os representantes do controle interno dos entes do poder executivo estadual nos 26 estados brasileiros e no Distrito Federal. A amostra selecionada compreende todos os entes do poder executivo estadual. A coleta de dados foi realizada por meio de questionário respondido pelos representantes das instituições. A segunda etapa foi realizada através de análise da média, moda e mediana dos resultados apresentados no questionário, bem como através do cálculo do coeficiente de correlação de Pearson, com verificação se as disponibilizações das práticas de controle social possuem associação com a boa governança pública. Os resultados da coleta de dados da pesquisa permitiram identificar que as práticas de controle social disponibilizadas à sociedade são: orçamento participativo, conferência pública, conselhos estaduais, representação/ denúncia, ouvidoria e página de transparência. O resultado evidenciou que, na visão dos respondentes, as práticas de controle social contribuem para a

Mestre em Administração pela Universidade Federal de Rondônia (UNIR) e professor do curso de Administração da Faculdade São Lucas. E-mail: fabiofes@ibest.com.br. Telefone: (69) 84550914.

2 Doutor e mestre em Engenharia de Produção pela Universidade Federal de Santa Catarina e professor pesquisador permanente credenciado do Programa de Pós-Graduação em Administração (PPGMAD) da UNIR. E-mail: Haroldo@unir.br 
governança no setor público, no entanto, disponibilizar práticas de controle social não necessariamente significa maior PIB dos estados.

Palavras-chave: Governança Pública. Controle Social. Relação de Agência. Gestão Pública.

\begin{abstract}
The present study objective to identify the existence of social control practices in the perception of the representatives of the internal control of the state executive branch checking if the disbursements of such practices are associated with public governance. The research is of applied nature, and quantitative research is descriptive of the aims. The population comprises representatives of the internal control of the entities of the state executive branch in 26 (twenty six) Brazilian states and the Federal District. The sample comprises all entities of the state executive branch. Data collection was conducted through a questionnaire answered by the representatives of the institutions. The second step was performed by analysis of the mean, mode and median of the results presented in the questionnaire, as well as calculating the Pearson correlation coefficient, check if the disbursements of the practices of social control are associated with good public governance. The results of the collection of data of the inquiry allowed to identify that the practices of social control made available to the society in entities federative being participatory budgeting, public conference, state advices, representation / denunciation, ombudsman and transparency page. The result showed up still what these practices of social control contribute with the governance in the public sector, since in the presented analysis, there is total or partial agreement, of the respondents, on this contribution to public governance, however the availability of social control practices do not necessarily mean that they are correlated with PIB per capita of the states, per capita income is correlated with good governance practices.
\end{abstract}

Keywords: Public Governance. Social Control. Agency Relation. Public Management.

\title{
1 Introdução
}

A falta de transparência governamental facilita a corrupção, emergindo, como um dos reflexos, a pouca credibilidade da sociedade em seus governantes e o afastamento da política. Os recorrentes escândalos da administração pública brasileira levam a crer que há uma limitação entre transparência instalada na administração pública e controle social exercido até então, ou em ambos. 
A preocupação mundial com a melhoria dos níveis de governança e accountability nunca foram maiores, seja no setor público ou privado, seja nas organizações internacionais e não governamentais. Hoje, há uma crença universal de que o aumento da transparência pode levar não somente a níveis mais significativos de accountability, como pode fazer isso de maneira muito mais eficaz em termos de custo. Prevalece, também, o amplo reconhecimento de que só se podem realizar mudanças duradouras, em atitudes e práticas, com a utilização da energia de todos os pontos de um triângulo de forças da sociedade, composto pelo Estado, o setor privado e a sociedade civil, não somente dentro dos países, mas além-fronteiras (EIGEN, 2002).

No caso brasileiro, a Constituição convocou a sociedade para exercer um controle sobre a gestão pública. Controle que ultrapassa o momento da eleição dos seus representantes, levando a sociedade a diversas formas de participação na gestão pública. Contudo, a previsão legal não é suficiente para o efetivo funcionamento do sistema denominado controle social. É necessário que as instituições públicas estejam preparadas para receber, tratar e aproveitar eficientemente as manifestações da sociedade. Não existirá controle social se as instituições públicas não estiverem abertas para receber o clamor da sociedade e não estiverem estruturadas para concretizar as demandas exigidas (PEREIRA, 2003).

O Estado, criado para atender o interesse coletivo, quando não alcança esse objetivo, precisa realinhar suas ações, visando o atendimento à sociedade. Porém, esta só terá condições de monitorar se seus interesses estão sendo atendidos quando os meios utilizados pelo Estado para dar transparência de seus atos forem tempestivos, compreensíveis e de fácil acesso.

Para os cidadãos exercerem controle sobre o(s) governo(s), é necessário que haja acesso à informação, pois, quanto mais bem informada a população, mais condições ela terá de exercer esse controle (BARBOSA, 2001). Outros autores retratam o conceito de governança pública como uma ação conjunta entre o setor público, o setor privado 
e a sociedade, na busca de soluções dos problemas sociais (MILANI; SOLINÍS, 2002; KAZANCIGIL, 2002; GONÇALVES, 2005; GOHN, 2007). Nesse contexto, controle social se alinha como instrumento para a governança pública. E para que essa ação conjunta seja estabelecida, é essencial responder à seguinte questão: quais práticas de controle social, na percepção dos representantes do controle interno, são disponibilizadas pelo poder executivo estadual à sociedade?

Espera-se que este artigo contribua para que as práticas de controle social disponibilizadas à sociedade ajudem no processo de tomada de decisões dos gestores públicos, pressupondo-se que ninguém possui o conhecimento soberano sobre todos os assuntos abordados pela gestão pública. Essas práticas são instrumentos de fomento, emancipação e fortalecimento do exercício individual e coletivo da cidadania. Elas apontam e permitem corrigir os canais por onde escoam os recursos públicos desviados, permitindo mudanças sociais concretas a partir da quebra do monopólio da política por certas classes.

Outra premissa deste trabalho refere-se ao fato de que essas práticas de controle social associadas à governança pública também ajudam a assegurar que os gestores respeitem os requisitos legais e criem valor nas suas relações com os stakeholders. Além disso, presume-se que a adoção dessas práticas contribui para alcançar o grau de confiança desejado pela sociedade em relação ao poder público.

\section{Fundamentação teórica}

Jensen e Meckling (1976) são os idealizadores da teoria da agência. Tal teoria traz a concepção de que, se cada parte for maximizando seus interesses, há boa razão para acreditar que o agente nem sempre agirá conforme o interesse do principal. Nesse ponto, surge o conflito de interesses, gerado pelo fato de que o agente e o principal podem possuir objetivos diferentes e conflitantes, ocupando posições diferenciadas. Surge, então, o problema de agência. Portanto, em muitas ocasiões, a tomada de decisão do agente pode ser influenciada por seus interesses pessoais. 
Para Eisenhardt (1985), a habilidade dos principais em saber se os agentes estão ou não agindo de acordo com seus interesses depende das informações disponíveis aos principais. Essas informações podem ser obtidas diretamente, pelo monitoramento direto das ações dos agentes, ou indiretamente, pelo acompanhamento dos resultados produzidos pelos agentes. Entretanto, como os resultados não dependem apenas dos agentes, eles, nesses casos, passam a assumir certa parcela do risco.

O problema de agência, segundo Hatch (1997), envolve o risco de o agente sobrepor seus interesses aos do principal. Para evitar os problemas de divergência de interesses, são realizados contratos, cujo objetivo é alinhar os interesses dos agentes com os de seus principais.

O problema de agência também ocorre na gestão pública, pois a delegação de poderes por parte da sociedade ao governante é vinculada à expectativa de que este aja de acordo com o interesse de quem the outorgou o poder. Tal situação é chamada de relação de agência. $O$ problema de agência ocorre quando o gestor eleito ou indicado para assumir um cargo público toma decisões para maximizar seus interesses pessoais em detrimento dos interesses daqueles que o elegeram ou indicaram.

A Constituição Federal de 1988 enfatiza que os recursos públicos devem ser geridos de forma a garantir o bem-estar social. No entanto, o governante, como representante do povo, possui certo nível de autonomia na gestão desses recursos e, em diversos casos, não está em consonância com os anseios coletivos, gerando o conflito de agência.

A governança pública é um instrumento relevante na minimização do conflito de agência, pois os estudos sobre o tema trazem alguns pontos comuns nos conceitos relacionados à governança: legitimidade de um espaço público em construção, onde são travados os encontros entre os atores sociais; repartição do poder entre os que governam e os que são governados; negociação entre os atores sociais, estabelecendo diferentes formas de redes e seus diferentes mecanismos de regulação; descentralização da autoridade e das funções ligadas ao ato de governar (DALLABRIDA, 2004). 
Streit e Klering (2004) fazem levantamento da literatura que também aponta para quatro características comuns encontradas em quinze diferentes conceituações de governança: existência de estruturas e mecanismos de regulação; ênfase maior no processo de interação em si, mais do que nos próprios resultados; atuação em rede das organizações e dos atores sociais; presença de objetivos e guias de ações comuns.

De todas essas revisões, resulta a ideia aproximada de governança como um mecanismo que busca regular relações entre atores e organizações em torno de questões públicas em que o Estado já não monopoliza as decisões, sem, contudo, eximir-se de participar das discussões a seu respeito, não raro coordenando-as. Trata-se, portanto, da regulação compartilhada de uma esfera pública (GOHN, 2007).

Na governança pública, o cidadão não é mais o "cliente" do Estado, não é aquele que se limita a fazer reivindicações ao Estado, mas um cidadão que encontra novas formas de participação nas decisões e novas formas de promoção da igualdade. Como destaca Nobre (2004, p. 30), "do ponto de vista desse modelo de cidadania em formação, é preciso influir na própria lógica da decisão estatal, ampliando mecanismos de participação e decisão nas diversas instâncias de deliberação e de decisão do Estado".

A discussão contemporânea sobre as diferentes formas de atuação do Estado tem o foco em mecanismos capazes de torná-lo eficaz e eficiente. De acordo com Araújo (2002), os conceitos de governabilidade e governança incorporam essas preocupações e, portanto, são tratados de forma diferenciada pela literatura recente. Na visão da mesma autora, os significados atribuídos ao termo "governança" surgiram num momento de interação entre fatores relacionados à democracia, ao capitalismo e à globalização, e passaram a exigir dos governos instrumentos e modelos que minimizassem os impactos sobre o Estado e corroborassem com a implementação de políticas públicas nas quais fossem contempladas a harmonização das relações público-privado, governo e sociedade.

De acordo com Born (2007), o conceito de governança refere-se ao conjunto de iniciativas, regras, instâncias e processos que permitem 
às pessoas, por meio de suas comunidades e organizações civis, exercerem o controle social, público e transparente das estruturas estatais e das políticas públicas, por um lado, e da dinâmica e das instituições do mercado, por outro, visando atingir objetivos comuns. Assim, governança abrange tanto mecanismos governamentais como informais e/ou não estatais. Significa a capacidade social (os sistemas, seus instrumentos e instituições) de dar rumo, ou seja, orientar condutas dos Estados, das empresas e das pessoas em torno de certos valores e objetivos de longo prazo para a sociedade.

As principais disciplinas que estudam o fenômeno governance são: as relações internacionais, com a concepção de um modelo colaborativo de relação interestatal e entre atores estatais e não estatais na solução de problemas coletivos internacionais; as teorias do desenvolvimento, que tratam a governança como um conjunto adequado de práticas democráticas e de gestão, e ajudam os países a melhorar suas condições de desenvolvimento econômico e social; a administração privada, com um conjunto de princípios básicos para aumentar a efetividade de controle por parte de stakeholders e autoridades de mercado sobre organizações privadas de capital aberto; e as ciências políticas e a administração pública, que tratam o conceito como um modelo horizontal de relação entre atores públicos e privados no processo de elaboração de políticas públicas (SECCHI, 2009). Neste trabalho, o fenômeno refere-se à governança na administração pública.

A definição dos atores no processo de governança pública não é simples, pois a gestão pública trata de diversos assuntos, em diversas áreas distintas, tendo atores distintos em cada área. A Figura 1 exemplifica alguns dos atores no processo de governança pública, dependendo do assunto abordado. 
Figura 1 - Exemplo de atores da governança pública.

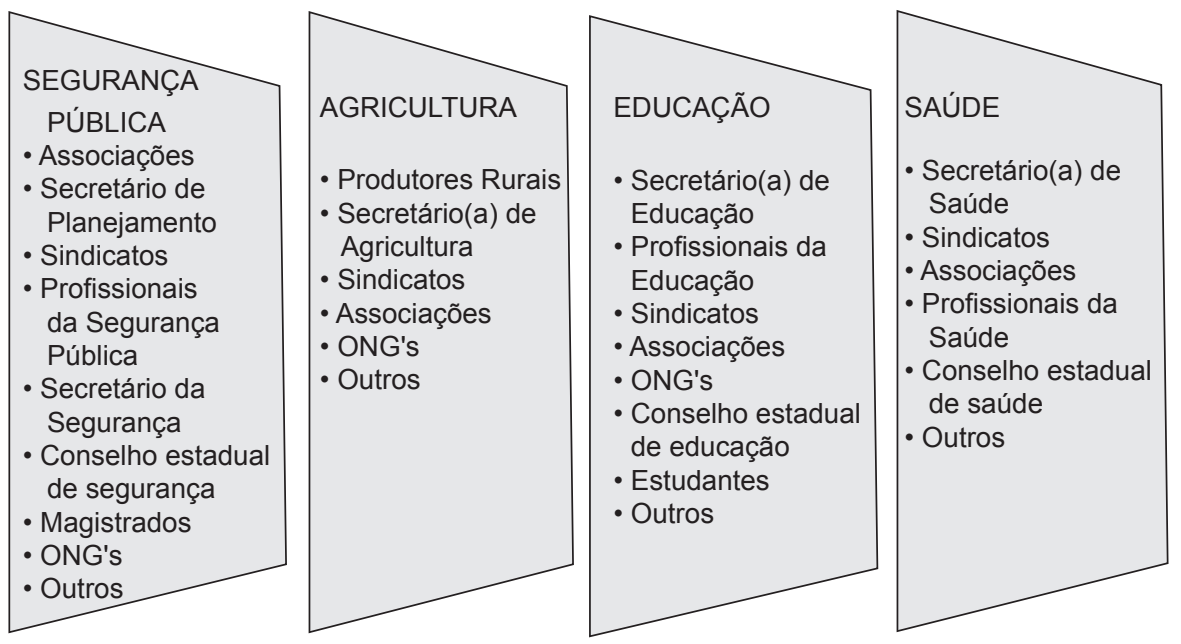

Fonte: Elaborado pelo autor.

Aênfase na participação da sociedade na gestão pública é evidente nos conceitos expostos anteriormente, e o controle social se inscreve no reconhecimento das condições necessárias para que se promova a democratização da gestão pública. No que se refere às concepções de controle social dos autores contemporâneos Correia (2000), Raichelis (2000), Carvalho (1995), Abreu (1999), Bravo (2006), Côrtes (1998) e Barros (1994), observa-se que todos analisam o controle social inserido na relação entre Estado e sociedade civil.

O conceito de controle social está relacionado com o envolvimento dos atores sociais no planejamento, monitoramento e verificação se tal plano foi executado, se suas ações alcançaram os objetivos esperados e se, efetivamente, proporcionou benefícios à sociedade. A própria Constituição de 1988 garante ao cidadão o direito de receber informações dos órgãos públicos (Art. $5^{\circ}, \mathrm{XXXIII)}$. Assegura, também, sua participação em colegiados de órgãos públicos em que seus interesses profissionais ou previdenciários sejam objeto de discussão. Com relação à formulação e fiscalização de políticas públicas, a Constituição prevê a participação da comunidade nas iniciativas sobre seguridade social (art. 194, VII), 
saúde (Art. 198, III), assistência social (art. 204, II), educação (art. 206, VI), cultura (art. $216, \S^{\circ}$ ), defesa e preservação do meio ambiente (art. 225) e criança e adolescente (art. 227, § $1^{\circ}$ ) (BRASIL, 1988). Como demonstrado, hoje, no Brasil há um significativo arcabouço jurídico e administrativo que propicia a participação do cidadão e da sociedade civil organizada na administração pública.

$\mathrm{Na}$ concepção atual, o governante toma as decisões no lugar da sociedade e em nome dela. Na concepção da governança pública, ninguém tem o conhecimento absoluto de todos os aspectos administrativos e gerenciais, necessitando de auxílio para governar (LOIOLA; MOURA, 1997 apud FREY, 2007). Esse auxílio vem dos diversos atores envolvidos no processo de governança. Os instrumentos de controle social inserem a sociedade no contexto de planejamento, execução, monitoramento e acompanhamento do resultado desejado, com o objetivo de alcançar o verdadeiro atendimento das necessidades da população.

Desse modo, a governança pública, o controle social e a relação de agência entre o governante e a sociedade devem estar integrados um ao outro para que a gestão cumpra sua missão de atender às necessidades de quem Ihe concedeu o poder, ou seja, a sociedade.

\section{Procedimentos metodológicos}

Os procedimentos metodológicos da pesquisa para o alcance dos objetivos foram: quanto à natureza, a pesquisa pode ser classificada como aplicada; com relação à forma de abordagem do problema, tratase de pesquisa quantitativa; quanto à forma de abordagem do problema, a pesquisa classifica-se como quantitativa, pois apresenta números quantificáveis que espelham as opiniões dos gestores das áreas de controladoria/controle interno sobre as práticas de controle social disponibilizadas à sociedade, identificação da unidade responsável pelo controle social, conhecimento e importância do controle social pelo servidor público e posicionamento do respondente quanto à relevância do controle social para os gestores e sua contribuição para a governança 
pública. Para isso, foi necessário efetuar os cálculos da média, moda, mediana e o coeficiente de correlação de Pearson, sendo utilizada a ferramenta SESTATNET (NASSAR; WRONSCKI; OHIRA, 2010).

O coeficiente de correlação de Pearson é uma medida do grau de relação linear entre duas variáveis quantitativas. Esse coeficiente varia entre os valores -1 e 1 . O valor 0 (zero) significa que não há relação linear, o valor 1 indica uma relação linear perfeita e o valor -1 também indica uma relação linear perfeita, mas inversa, ou seja, quando uma das variáveis aumenta a outra diminui. Quanto mais próximo estiver de $1 \mathrm{ou}$ -1 , mais forte é a associação linear entre as duas variáveis. O coeficiente de correlação de Pearson é normalmente representado pela letra $\mathbf{r}$ e a sua fórmula de cálculo é a seguinte:

$$
r=\frac{\sum\left(x_{i}-\bar{x}\right)\left(y_{i}-\bar{y}\right)}{\sqrt{\left(\sum\left(x_{i}-\bar{x}\right)^{2}\right)\left(\sum\left(y_{i}-\bar{y}\right)^{2}\right)}}
$$

Segundo Callegari-Jacques (2003), o coeficiente de correlação pode ser avaliado qualitativamente da seguinte forma:

Se $0,00<\rho^{\wedge}<0,30$, existe fraca correlação linear

Se $0,30 \leq \rho^{\wedge}<0,60$, existe moderada correlação linear

Se $0,60 \leq \rho^{\wedge}<0,90$, existe forte correlação linear

Se $0,90 \leq \rho^{\wedge}<1,00$, existe correlação linear muito forte

Quanto aos objetivos, é descritiva, visando descrever a opinião de determinada população. A população compreende os representantes do controle interno dos entes do poder executivo estadual nos 26 estados brasileiros e no Distrito Federal. A amostra selecionada compreende todos os entes do poder executivo estadual. A coleta de dados foi realizada através de questionário respondido pelos representantes das instituições. A segunda etapa foi realizada através de análise da média, moda e mediana dos resultados apresentados no questionário, bem como através do cálculo do coeficiente de correlação de Pearson, demonstrando o nível de associação das variáveis e verificação se as disponibilizações das práticas de controle social possuem associação com a boa governança pública. O período de coleta por meio de 
questionário estendeu-se de 24/03/2011 a 26/05/2011 e apenas os representantes dos estados do Amapá e Piauí não responderam ao questionário.

\section{Análise dos resultados}

A análise e discussão dos resultados estão divididas em duas etapas. Na primeira, a discussão baseou-se no resultado obtido frente à percepção das práticas de controle social coletadas por questionário enviado, através de e-mail, às controladorias estaduais. Na segunda etapa, foi realizada a análise de correlação de Pearson.

A questão 1 pede a indicação das práticas de controle social que são disponibilizadas pelo governo estadual à sociedade. A análise dos resultados da questão 1 com a mediana está apresentada no Gráfico 1.

Gráfico 1 - Práticas de controle social disponibilizadas

Quais as práticas de controle social são disponibilizadas pelo governo estadual à sociedade?

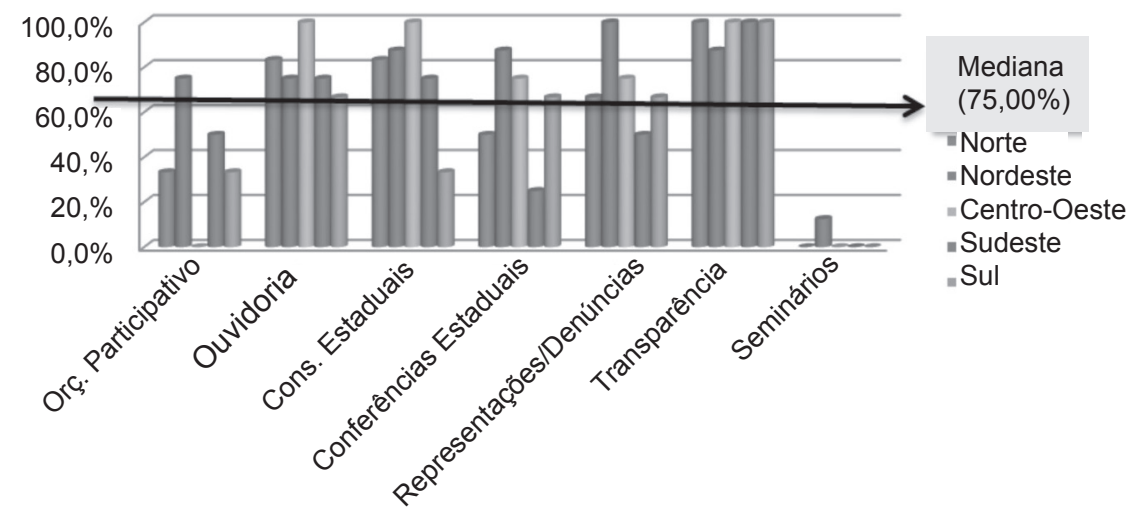

Fonte: Elaborado pelo autor com base nos dados da pesquisa.

A mediana é o ponto que divide uma determinada distribuição de valores em duas metades. Na questão em análise, constata-se que foi apurada no percentual de $76 \%$. Para não retirar percentuais significativos 
sobre o gráfico apresentado, foram considerados os valores da mediana a partir de $75 \%$. No Gráfico 1, o resultado demonstra que:

Orçamento participativo (OP): exceto a região Nordeste, todas as demais regiões apresentam disponibilização da prática abaixo da mediana, ou seja, o orçamento participativo é a prática de controle social que está $50 \%$ abaixo dos resultados da amostra. A ausência dessa prática de controle social diminui a oportunidade de participação dos atores sociais nos processos de planejamento, execução e avaliação orçamentária dos entes governamentais.

Ouvidoria (OUV): exceto a região Sul, o resultado das demais regiões do país demonstra que a prática de ouvidoria é disponibilizada, no mínimo, em $75 \%$ dos estados em cada região.

Conselhos Estaduais (CONS): com exceção da região Sul, os resultados demonstram que essa prática é disponibilizada, no mínimo, em $75 \%$ dos estados em cada região.

Conferências Estaduais (CONF): as regiões Nordeste, CentroOeste e Sul são aquelas em que, no mínimo, 75\% dos estados disponibilizam essa prática.

Representações/Denúncias (R/D): no mínimo, 75\% dos estados disponibilizam a referida prática.

Página de Transparência (TRANSP): a prática de disponibilizar a página de transparência está presente em todas as regiões do país, acima da mediana apurada. É válido ressaltar que, exceto o estado da Paraíba, todos os outros que enviaram os questionários respondidos informaram que disponibilizam essa prática.

$\mathrm{Na}$ análise geral, observa-se que a frequência mais significativa dentre as práticas de controle social disponibilizadas é a página de transparência, com $96 \%$ dos respondentes confirmando a prática em seus estados, seguida das práticas de disponibilização das ouvidorias e dos conselhos estaduais (80\%). A prática de representação/denúncia aparece logo a seguir, com afirmativa de $76 \%$ dos respondentes. Posteriormente, aparece a prática de conferências estaduais (64\%) e, 
por último, a prática de disponibilizar o orçamento participativo (44\%). A abertura de canais de participação entre o governo e a sociedade está embutida na concepção de governança, mas a governança enfatiza o aumento do poder social (CARNEIRO, 2004). No geral, constata-se que as práticas de controle social, de acordo com os respondentes, são disponibilizadas à sociedade, levando a possibilidade de fortalecimento da participação da sociedade nos processos de decisão política; no entanto, a prática de orçamento participativo necessita de implantação na maior parte do país.

A segunda pergunta tem o objetivo de saber quais as práticas de controle social estão em processo de implantação. Na Tabela 1, percebese o desejo dos gestores em disponibilizar a prática de conferências estaduais (7), que, na análise a nível nacional, ocupa a penúltima posição das práticas disponibilizadas à sociedade. Caso ocorra a implantação em todos os estados onde os respondentes informam que está em implantação, a referida prática estará classificada em segundo lugar na disponibilização à sociedade. Por outro lado, a prática de orçamento participativo está disponível em apenas $44 \%$ dos estados pesquisados e não se observa, nas respostas apresentadas, o desejo do gestor em disponibilizá-la a sociedade.

Tabela 1 - Percentual de disponibilização das práticas de controle social

\begin{tabular}{l|c|c|c|c|c|c}
\hline Práticas & O P & OUV & CONS & CONF & R/D & TRANSP \\
\hline $\begin{array}{l}\text { Práticas } \\
\text { disponibilizadas }\end{array}$ & 11 & 20 & 20 & 16 & 19 & 24 \\
\hline $\begin{array}{l}\text { \% em relação à } \\
\text { amostra }\end{array}$ & $44 \%$ & $80 \%$ & $80 \%$ & $64 \%$ & $76 \%$ & $96 \%$ \\
\hline $\begin{array}{l}\text { Práticas em } \\
\text { implantação }\end{array}$ & 2 & 2 & 1 & 7 & 1 & 1 \\
\hline $\begin{array}{l}\text { \% em relação à } \\
\text { amostra }\end{array}$ & $8 \%$ & $8 \%$ & $4 \%$ & $28 \%$ & $4 \%$ & $4 \%$ \\
\hline $\begin{array}{l}\text { Previsão de } \\
\text { disponibilidade }\end{array}$ & $\mathbf{5 2 \%}$ & $\mathbf{8 8 \%}$ & $\mathbf{8 4 \%}$ & $\mathbf{9 2 \%}$ & $\mathbf{8 0 \%}$ & $\mathbf{1 0 0 \%}$ \\
\hline \begin{tabular}{l} 
Classificação \\
\hline
\end{tabular} & $\mathbf{6}^{\mathrm{a}}$ & $\mathbf{3}^{\mathbf{0}}$ & $4^{\mathrm{a}}$ & $2^{\mathrm{a}}$ & $5^{\mathrm{a}}$ & $1^{\mathrm{a}}$ \\
\hline
\end{tabular}

Fonte: Elaborado pelo autor com base nos dados da pesquisa. 
A terceira questão busca conhecer os canais de comunicação que o governo do estado disponibiliza à sociedade. O Gráfico 2 demonstra 0 resultado geral da pesquisa.

Gráfico 2 - Canais de comunicação das práticas de controle social.

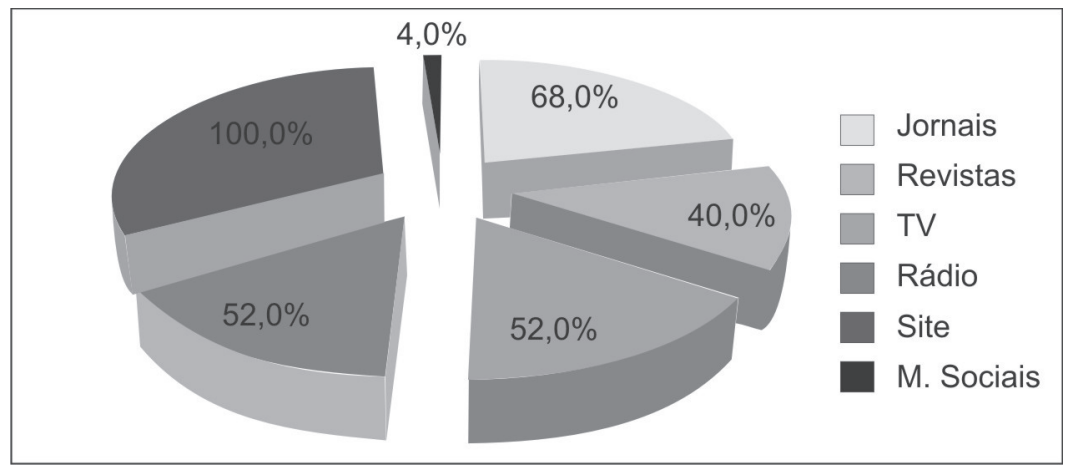

Fonte: Elaborado pelo autor com base nos dados da pesquisa.

A pesquisa demonstrou que o canal de comunicação mais utilizado para dar ampla divulgação das práticas de controle social são os sites governamentais (100\%). Outros canais de comunicação utilizados são os jornais (68\%), a TV e o rádio (52\%), revistas (40\%) e uma novidade representada pelas mídias sociais utilizadas pelo governo da Paraíba. A pesquisa IBOPE referente ao quarto trimestre de 2010 relata que o número de pessoas com acesso à internet no Brasil atingiu 73,9 milhões, representando um crescimento de $9,6 \%$ em relação ao quarto trimestre de 2009. Observa-se que a disponibilização das informações nos sites governamentais pode ser divulgada em maior amplitude, com melhor detalhamento e a cada ano. Com a ampliação do acesso à internet, mais pessoas poderão ser alcançadas por essas informações, favorecendo a participação mais ampla na gestão e no controle efetivo da aplicação dos recursos públicos.

A quarta questão indaga sobre qual o percentual de secretarias que disponibilizam pelo menos uma das práticas de controle social. A maior parte $(56,5 \%)$ dos respondentes afirmou que de $81 \%$ a $100 \%$ das 
secretarias estaduais disponibilizam pelo menos uma das práticas de controle social e quatro representantes informaram que de $61 \%$ a $80 \%$ das secretarias disponibilizam ao menos uma prática. Os representantes dos estados do Espírito Santo e Santa Catarina informaram que não possuem os dados precisos para responder à questão. Essa disponibilização é essencial para que, em todas as unidades, as práticas de controle social sejam disseminadas, conhecidas e utilizadas.

A questão 5 tem o objetivo de saber em qual nível as práticas de controle social têm atendido às demandas da sociedade. Se elas não atendem aos anseios da sociedade, não devem ser implantadas, ou devem ser adaptadas para atender ao objetivo pelo qual foram criadas. As respostas foram escalonadas nos seguintes níveis: excelente, adequado, pouco adequado, inadequado e ruim. O resultado está apresentado no Gráfico 3.

Gráfico 3 - Nível de atendimento à sociedade

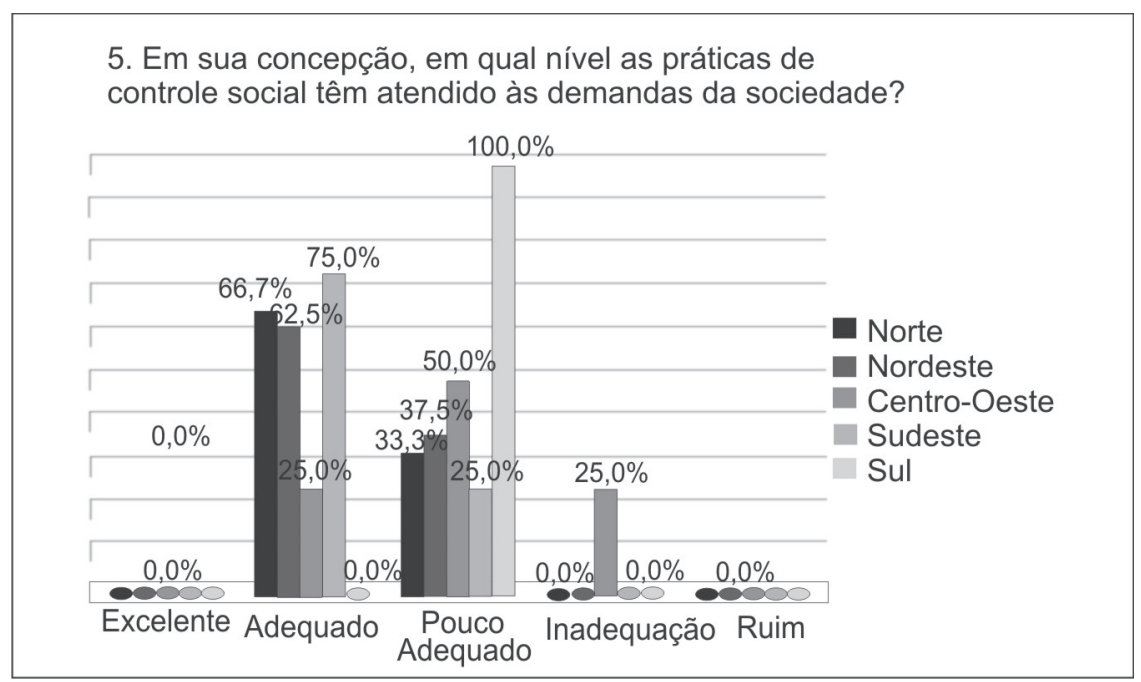

Fonte: Elaborado pelo autor com base nos dados da pesquisa.

As respostas estão concentradas nos níveis "adequado" (52\%) e "pouco adequado" (44\%). A partir da observação das respostas apresentadas, pode-se inferir que há necessidade de aprimoramento 
das práticas de controle social e, ainda, necessidade de se implementar práticas mais eficazes e acessíveis à sociedade. Efetuando a comparação do resultado dos estados que disponibilizam $100 \%$ das práticas evidenciadas no estudo em relação às práticas informadas e sua adequação, conforme o Quadro 1, quatro estados consideram que suas práticas de controle social apresentam nível "adequado" de atendimento às demandas da sociedade. O fato relevante está em relação aos estados de Pernambuco e do Rio Grande do Sul, pois, apesar de os respondentes informarem que o ente governamental disponibiliza todas as práticas relacionadas na pesquisa, em sua opinião, o atendimento à sociedade está no nível "pouco adequado". O resultado sugere que essas práticas de controle social possuam mais potencial do que eficácia, conforme Quadro 1.

Quadro 1 - Relação entre práticas confirmadas e o nível de atendimento à sociedade

\begin{tabular}{lcc}
\hline Estado & $\begin{array}{c}\text { \% de disponibilização das } \\
\text { práticas informadas }\end{array}$ & Nível de atendimento à sociedade \\
\hline BA & $100,0 \%$ & Adequado \\
CE & $100,0 \%$ & Adequado \\
PE & $100,0 \%$ & Pouco Adequado \\
SE & $100,0 \%$ & Adequado \\
ES & $100,0 \%$ & Adequado \\
RS & $100,0 \%$ & Pouco Adequado \\
\hline
\end{tabular}

Fonte: Elaborado pelo autor com base nos dados da pesquisa.

Efetuando o cálculo de correlação de Pearson, em que DISPON é o resultado das respostas da questão 1 e NATEND é o resultado da questão 5, temos a implicação na Tabela 2. 
Tabela 2 - Correlação de Pearson - DISPON x NATEND

\begin{tabular}{lll}
\hline & DISPON & NATEND \\
\hline Média & 72.000000 & 69.600000 \\
Desvio-padrão & 22.926022 & 11.718931 \\
Casos válidos & 25 & \\
Coeficiente r de Pearson (X,Y) & 0.111352 & \\
Medida estatística: $\mathbf{t}$ & 0.537365 & \\
Graus de liberdade & 23 & \\
$\mathbf{p}_{\text {valor }}$ & 0.2980882 & \\
\hline
\end{tabular}

Fonte: Elaborado pelo autor com base nos dados da pesquisa.

O resultado demonstra que a disponibilização das práticas de controle social não necessariamente significa que elas atendam às demandas da sociedade, pois o resultado do cálculo do coeficiente $(0,111352)$, de acordo com Callegari-Jacques (2003), demonstra fraca correlação linear.

A questão 6 pergunta se a instituição possui uma unidade/ secretaria/departamento responsável por implementar políticas e práticas de controle social. Se a resposta for sim, pede-se para informar o nome dessa unidade/secretaria/departamento. O objetivo desse tópico é evidenciar a unidade responsável pela implantação das políticas e práticas de controle social em cada ente federativo.

A pesquisa apresenta 17 respondentes afirmando que o governo de seu estado possui unidade responsável por implementar políticas e práticas de controle social. Das afirmativas confirmatórias, 70,58\% dos respondentes informaram que a unidade responsável está ligada à controladoria estadual, 17,4\% afirmaram que está ligada às secretarias de planejamento e $11,76 \%$ disseram que está ligada à Secretaria da Fazenda. Cabe observar que as controladorias se originaram das Secretarias de Fazenda da maior parte dos estados brasileiros, portanto, apesar de não estarem confirmadas como unidades de controladoria, há um elo entre elas. O resultado dessa questão dá sustentação à escolha da população para a realização da pesquisa. 
O item sobre o servidor e o controle social foi desenvolvido objetivando verificar o conhecimento e a importância das práticas de controle social para o servidor público, conforme as questões 7 e 8 . A sétima pergunta tem o objetivo de saber se o servidor público tem conhecimento das práticas de controle social. As melhores práticas de governança pública requerem um forte compromisso de todos os participantes, para serem implementados todos os elementos da governança corporativa (BARRET, 2002). A interação dos servidores com o conhecimento das práticas de controle social é essencial para uma boa governança. A resposta à questão formulada está compilada no Gráfico 4.

Gráfico 4 - Conhecimento do servidor sobre as práticas

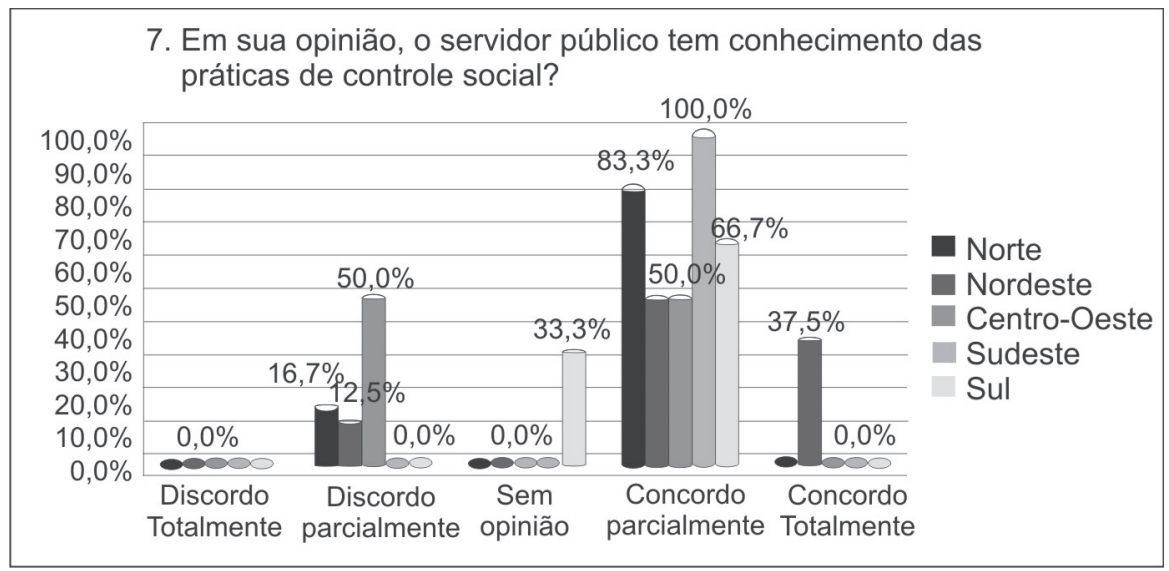

Fonte: Elaborado pelo autor com base nos dados da pesquisa.

Dos respondentes da região Norte, 83,3\% assinalaram "concordo parcialmente" quanto ao conhecimento do servidor público sobre as práticas de controle social. A distribuição das respostas na região Nordeste está em 50\% para "concordo parcialmente" e 37,5\% para "concordo totalmente", ou seja, 87,5\% concordam parcial ou totalmente que o servidor público tem conhecimento das práticas de controle social. Há um equilíbrio quanto à opinião dos respondentes na região Centro-Oeste, pois 50\% "discordam parcialmente" e $50 \%$ "concordam 
parcialmente" sobre o conhecimento do servidor público quanto às práticas de controle social. Na região Sudeste, $100 \%$ dos respondentes "concordam parcialmente" que o servidor público tem conhecimento das práticas de controle social. Na região Sul, 66,7\% dos respondentes "concordam parcialmente" que o servidor público tem conhecimento das práticas de controle social.

A oitava questão tem a finalidade de verificar se o servidor sabe a importância do controle social. A desconfiança do servidor em relação ao cidadão (SILVA, 2009) pode ser minimizada a partir do momento em que ele tem conhecimento da importância do controle social, percebendo que o cidadão é um parceiro para que a gestão pública alcance os objetivos almejados. Na análise geral, dos 25 respondentes, 17 (68\%) concordaram parcialmente quanto ao conhecimento, pelo servidor público, das práticas de controle social. Dos 17, 15 (88,24\%) concordaram parcialmente sobre se o servidor público sabe a importância do controle social.

Efetuando o cálculo de correlação de Pearson, onde CONPRAT é a resposta da questão 7 e IMPORT representa a resposta da questão 8, temos o resultado na Tabela 3 .

Tabela 3 - Correlação de Pearson - CONPRAT X IMPORT

\begin{tabular}{lll}
\hline & CONPRAT & IMPORT \\
\hline Média & 3.760000 & 3.640000 \\
Desvio-padrão & 0.879394 & 0.810350 \\
\cline { 1 - 1 } Casos válidos & 25 & \\
Coeficiente r de Pearson $(\mathrm{X}, \mathrm{Y})$ & 0.692285 & \\
Medida estatística: $\mathrm{t}$ & 4.600840 & \\
Graus de liberdade & 23 & \\
pvalor & 0.0000631 & \\
\hline
\end{tabular}

Fonte: Elaborado pelo autor com base nos dados da pesquisa.

O cálculo de correlação das variáveis CONPRAT (Conhecimento das práticas de controle social) e IMPORT (Importância das práticas de 
controle social) obteve o resultado de $r=0,692285$ e, de acordo com Callegari-jacques (2003, p. 90), apresenta forte correlação linear positiva entre as duas variáveis, ou seja, conforme o servidor toma conhecimento das práticas de controle social ele tende a se conscientizar sobre a importância dessas práticas. As dificuldades para o cidadão acessar as informações de interesse público são decorrentes da falta de cultura cívica, tanto da comunidade quanto dos servidores públicos, que, no geral, tratam informação como se fosse um "segredo de estado" (SILVA, 2009). O conhecimento da importância do controle social tende a influenciar o servidor a perceber que a informação pertence à sociedade e qualquer cidadão que necessite esclarecimento deve ser prontamente atendido.

A questão 9 trata sobre qual a relevância do controle social para os gestores públicos. Os resultados são apresentados no Gráfico 5.

Gráfico 5 - Relevância do controle social para os gestores.

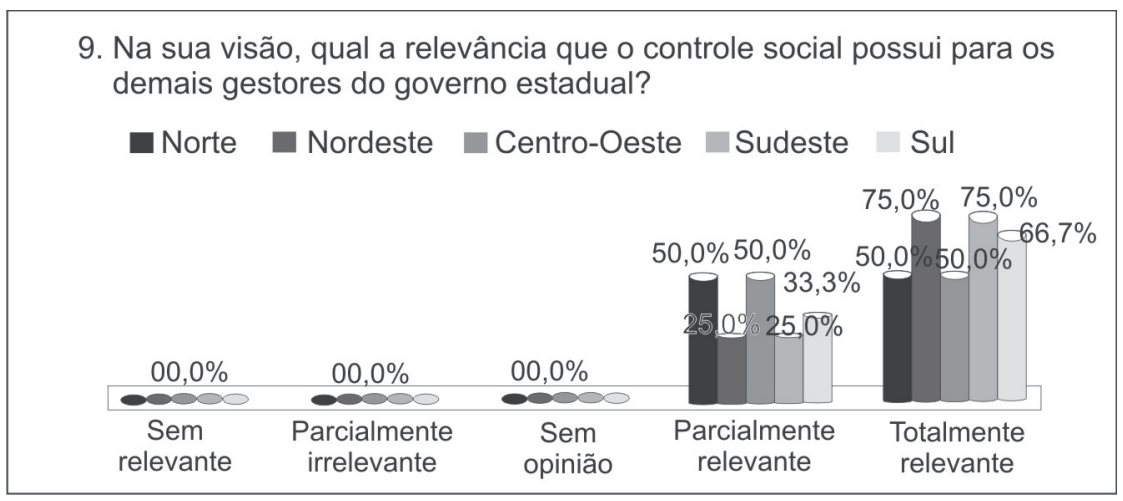

Fonte: Elaborado pelo autor com base nos dados da pesquisa.

Com relação ao Gráfico 5, 100\% dos respondentes assinalaram que, para os gestores dos governos estaduais, o nível de relevância do controle social está entre "parcialmente relevante" e "totalmente relevante". A resposta demonstra a percepção dos respondentes, porém, para que isso se torne uma realidade, os gestores precisam estimular a instituição na construção, o compartilhamento e a divulgação das práticas 
de controle social, cooperando para que os usuários das informações prestadas possam obtê-las de forma clara, objetiva, compreensível e tempestiva.

A décima questão pergunta se as práticas de controle social contribuem para a governança na gestão pública. As respostas estão apresentadas no Gráfico 6.

\section{Gráfico 6 - Contribuição para governança pública}

10. Em sua concepção, as práticas de controle social contribuem para governaça na gestão pública em seu estado?

Norte $\square$ Nordeste Centro-Oeste Sudeste Sul $\quad 100,0 \%$

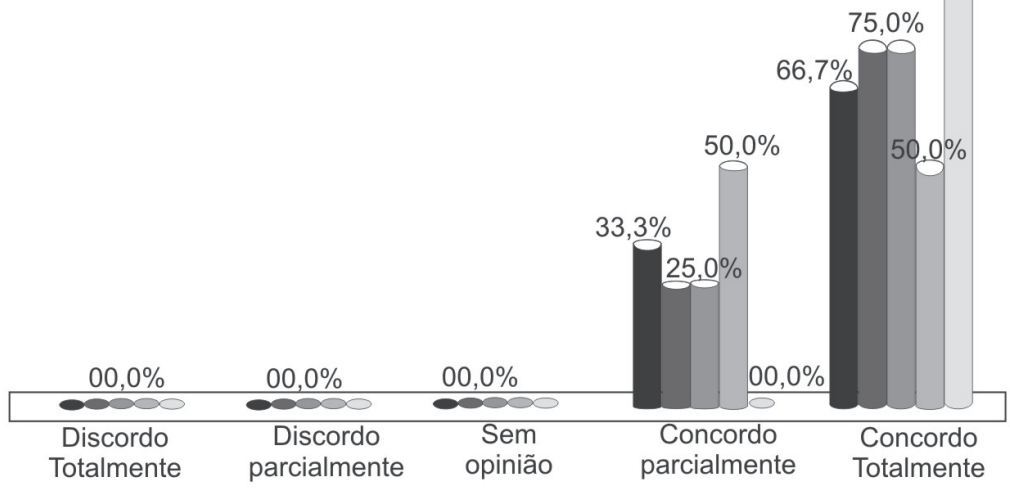

Fonte: Elaborado pelo autor com base nos dados da pesquisa.

A governança na gestão pública está pautada na interação de diversos atores na elaboração, execução, monitoramento e avaliação de resultados. Essa interação se dá através das práticas de controle social. Para que isso tenha efetividade, é necessário que os gestores estejam dispostos a incentivar a participação popular nesse processo. Cabe avaliar, como ponto positivo, se as práticas de controle social contribuem para a governança na gestão pública em seu estado. 0 resultado demonstrou que $28 \%$ dos entrevistados responderam que "concordam parcialmente" e $72 \%$ "concordam totalmente". 
A última análise foi realizada efetuando o cálculo de correlação de Pearson, em que DISPON é o resultado das respostas da questão $1 \mathrm{e}$ PIB é o resultado do Produto Interno Bruto per capita de cada estado, no ano de 2009, conforme a Tabela 4.

Tabela 4 - Correlação de Pearson - DISPON x PIB

\begin{tabular}{lll}
\hline & DISPON & \% PIB \\
\hline Média & 72.000000 & 29.845200 \\
Desvio-padrão & 22.926022 & 18.148093 \\
\hline Casos válidos & & \\
Coeficiente r de Pearson (X,Y) & -0.108780 & \\
Medida estatística: $\mathbf{t}$ & -0.524806 & \\
Graus de liberdade & 23 & \\
$\mathbf{P}_{\text {valor }}$ & 0.3023702 & \\
\hline
\end{tabular}

Fonte: Elaborado pelo autor com base nos dados da pesquisa.

O Banco Mundial afirma que a melhoria de ações governamentais tem efeito significativo na renda per capita de uma nação (WORLD BANK INSTITUTE, 2006), ou seja, renda mais alta está diretamente relacionada com a prática da boa governança. As práticas de controle social são práticas de boa governança pública (BORN, 2007) e, por isso, quanto mais os estados disponibilizam práticas de controle social, maior a renda per capita desses estados.

O resultado demonstra que a disponibilização das práticas de controle social não necessariamente significa que elas estão correlacionadas com o PIB per capita dos estados, pois o resultado do cálculo do coeficiente $(-0, X 08780)$, de acordo com Callegari-Jacques (2003), demonstra fraca correlação linear.

\section{Considerações finais}

O objetivo deste trabalho foi identificar a existência das práticas de controle social na percepção dos representantes do controle interno do poder executivo estadual, verificando se elas possuem associação com a governança pública. 
Quanto ao primeiro objetivo, o estudo identificou que as práticas de controle social utilizadas no Brasil são a transparência, os conselhos de políticas públicas, as conferências públicas, as representações/ denúncias, as ouvidorias e o orçamento participativo, sendo a página de transparência a prática evidenciada em $100 \%$ da amostra em todas as regiões do país, exceto na região Nordeste. Por sua vez, as práticas respondidas como disponibilizadas à sociedade são as ouvidorias e os conselhos estaduais, com frequência afirmativa de $80 \%$ dos respondentes. Após esses itens, temos a prática de representação/ denúncia, com $76 \%$ dos respondentes afirmando que ela é disponibilizada à sociedade. A menor frequência de respostas foi para a prática de orçamento participativo, pois apenas $44 \%$ dos respondentes confirmaram que o poder executivo estadual a disponibiliza. Apesar de a prática de orçamento participativo estar disponível apenas em $44 \%$ dos estados pesquisados, não se observa o desejo do gestor em disponibilizá-la à sociedade. Também ficou demonstrado que o canal de comunicação mais utilizado para dar ampla divulgação das práticas de controle social são os sites governamentais (100\%). Outro fator importante no resultado da pesquisa foi que $50 \%$ dos respondentes pontuaram que as secretarias governamentais disponibilizam, no mínimo, uma prática de controle social. Cumpre frisar que o primeiro objetivo foi alcançado com o resultado da pesquisa objeto de estudo.

O segundo objetivo foi verificar a associação entre a disponibilização das práticas de controle social e a boa governança pública. Na visão dos respondentes, as práticas de controle social contribuem para a governança no setor público, pois, na análise apresentada, $100 \%$ dos respondentes concordam parcial ou totalmente que as práticas de controle social contribuem para a governança pública. Contudo, a análise estatística através do coeficiente de correlação de Pearson demonstrou fraca correlação linear entre as variáveis práticas disponibilizadas e o PIB per capita dos Estados, ou seja, a simples disponibilização de práticas de controle social não necessariamente contribui para o aumento da renda per capta dos estados. 


\section{Referências}

ABREU, Marina Maciel. A relação entre o Estado e a sociedade civil: a questão dos conselhos de direitos e a participação do Serviço Social. Serviço Social \& Movimento Social, São Luís, v. 1, p. 61-76, jul./ dez.1999.

ARAÚJO, Vinícius de Carvalho. A conceituação de governabilidade e governança, da sua relação entre si e com o conjunto da reforma do Estado e do seu aparelho. Texto para discussão n. 45. Disponível em: <http://www.enap.gov.br/index.php?option=content\&task=view\& $i d=259>$. Acesso em: 30 jan. 2007.

BARBOSA, Sandra Pires. Direito à informação e controle social da atividade econômica. Jus Navigandi, Teresina, ano 6, n. 51, 1 out. 2001. Disponível em: <http://jus.com.br/revista/texto/2078>. Acesso em: 4 jan. 2010.

BARRETT, Pat. Achieving better practice corporate governance in the public sector. AM Auditor General for Austrália. 2002. Disponível em: <http://www.anao.gov.au/uploads/documents/Achieving_Better_ Practice_Corporate_Governance_in_the_Public_Sector1.pdf $>$. Acesso em: 15 set. 2009.

BARROS, Maria Elizabeth Diniz. O controle social e o processo de descentralização dos serviços de saúde. In: INCENTIVO à participação popular e o controle social no SUS. Brasília, DF: Ministério da Saúde, Brasília, 1994. (Textos técnicos para conselheiros de saúde).

BORN, Rubens H. Governança e sustentabilidade: desafios para todos. In: FÓRUM BRASILEIRO DE ONGS E MOVIMENTOS SOCIAIS PARA O MEIO AMBIENTE E O DESENVOLVIMENTO. Governança ambiental internacional: perspectivas, cenários e recomendações. São Paulo: Vitae Civilis, 2007.

BRASIL. Constituição (1988). Constituição da República Federativa do Brasil: promulgada em 5 de outubro de 1988. Presidência da República Federativa do Brasil. Disponível em: <http://www.presidencia.gov.br/ 
legislacao>. Acesso em: 5 nov. 2009.

BRAVO, Maria Inês Souza. Desafios atuais do controle social no sistema único de saúde (SUS). Serviço Social \& Sociedade, São Luís, n. 88, nov. 2006.

CALLEGARI-JACQUES, Sidia M. Bioestatística: princípios e aplicações. Porto Alegre: Artmed, 2003. 255 p.

CARNEIRO, Carla Bronzo Ladeira. Governança e Accountability: algumas notas introdutórias. Texto para Discussão $n^{0} 13$. Disponível em: <http://www.eg.fjp.mg.gov.br>. Acesso em: 30 jan. 2007.

CARVALHO, Antonio Ivo de. Conselhos de saúde: participação cidadã e social. Rio de Janeiro: FASE/IBAM, 1995.

CORREIA, Maria Valéria Costa. Que controle social? Os conselhos de saúde como instrumento. Rio de Janeiro: Fiocruz, 2000.

CORTES, S. M. V. Conselhos municipais de saúde: a possibilidade dos usuários participarem e os determinantes da participação. Ciência \& Saúde Coletiva, Rio de Janeiro, v. 3, n. 1, p. 5-17, 1998.

DALLABRIDA, V. R. (2004) ?Governança territorial e políticas públicas: para a institucionalização de uma prática de concertação públicoprivada? In: BÜTTENBENDER, P. L.; RIGHI, L. (Org.). Políticas públicas e saúde. ljuí: Ed. Unijuí, 2004. p. 10-25. (Cadernos Unijuí, série Gestão Pública, 3).

EIGEN, Peter. Corrupção é um desafio. In: SPECK, Bruno W. (Org.). Caminhos da transparência. Campinas, SP: Unicamp, 2002.

EISENHARDT, Katheleen M. Agency theory: an assessment and review. Academy of Management Review, Briarcliff Manor, v. 14, n. 1, p. 57-74, jan. 1989. Disponível em:< http://www.ppge.ufrgs.br/giacomo/ arquivos/ecop26/eisenhardt-1989.pdf > . Acesso em: 10 mar. 2010.

FREY, Klaus. Governança urbana e participação pública. RACEletrônica, Rio de Janeiro, v.1, n.1, p.136-150, jan./abr. 2007. 
Disponível em: <http://www.fag.edu.br/professores/pos/MATERIAIS/ MBA\%20em\%20Gest\%E3o\%20Empresarial/Material\%20Prof.\%20 Anderson/artigo\%20adm\%2018.pdf>. Acesso em: 3 mar. 2010.

GOHN, M.G. Conselhos gestores e participação sociopolítica. 3. ed. São Paulo: Cortez, 2007.

GONÇALVES, Alcindo. O conceito de governança. In: CONSELHO NACIONAL DE PESQUISA E PÓS-GRADUAÇÃO EM DIREITO, 15., 2006, Manaus. Anais... Disponível em: <http://www.conpedi.org/ manaus/arquivos/Anais/Alcindo\%20Goncalves.pdf>. Acesso em: 15 mar. 2010.

$\mathrm{HATCH}, \mathrm{M}$. J. Organization theory: modern symbolic and postmodern perspectives. New York: Oxford University Press, 1997. cap. 2., p. 41-51. Disponível em: <http://ebooksfactory.org/ebooks/organizationtheory-modern-symbolic-and-postmodern-perspectives.html>. Acesso em: 5 set. 2009 .

JENSEN, Michael C.; MECKLING, William H. Theory of the firm: managerial behavior, agency costs and ownership structure. Journal of Financial Economics, New York, v. 3, n. 4, p. 305-360, Oct. 1976.

KAZANCIGIL, A. A regularização social e a governança democrática da mundialização. Traduzido por Luís Augusto Junges Lopes. In: MILANI, C.; ARTURI, C.; SOLINÍS, G. (Org.). Democracia e governança mundial: que regulações para o século XXI?. Porto Alegre: Ed. UFRGS/UNESCO, 2002. p. 47-62.

MILANI, C.; SOLINÍS, G. Pensar a democracia na governança mundial: algumas pistas para o futuro. In: MILANI, C.; ARTURI, C.; SOLINÍS, G. (Org.). Democracia e governança mundial: que regulações para o século XXI? Porto Alegre: Ed. Universidade/UFRGS/UNESCO, 2002. p. 266-291.

NASSAR, Silvia M.; WRONSCKI, Vilson R.; OHIRA, Masanao. SEstatNet: Sistema Especialista para o Ensino de Estatística na Web. Disponível em: <http://www.sestat.net>. Acesso em: 12 dez. 2011. 
NOBRE, M. Participação e deliberação na teoria democrática: uma introdução. In: COELHO, V. S.; NOBRE, M. (Org.). Participação e deliberação: teoria democrática e experiências institucionais no Brasil Contemporâneo. São Paulo: Ed. 34, 2004. p. 21-40.

PEREIRA, Ricardo. M. O controle social na gestão pública: as funções de fiscalização e de ouvidoria dos Tribunais de Contas do Brasil. 2003. 117 f. Dissertação (Mestrado Profissionalizante em Gestão Pública para o Desenvolvimento do Nordeste)- Universidade Federal de Pernambuco, Recife, 2003.

RAICHELIS, Raquel. Os conselhos de gestão no contexto internacional. Revista Pólis, São Paulo, n. 37, p. 41-45, 2000.

SECCHI, Leonardo. Modelos organizacionais e reformas da administração pública. Rev. Adm. Pública, Rio de Janeiro, v. 43, n. 2, abr. 2009. Disponível em <http://www.scielo.br/scielo.php?script=sci_ arttext\&pid=S0034-76122009000200004\&Ing=pt\&nrm=iso>. Acesso em: 8 jan. 2010.

SILVA, Gecilda Esteves. Os tribunais de contas e o controle social: a proposta de criação de uma ouvidoria para o tribunal de contas do Estado do Rio de Janeiro e sua importância no processo democrático fluminense. 2009. 122 f. Dissertação (Mestrado em Administração Pública)-Fundação Getúlio Vargas, Rio de Janeiro, 2009.

STREIT, R. E.; KLERING, L. R. Governança pública sob a perspectiva dos sistemas complexos. In: ENCONTRO DE ADMINISTRAÇÃO PÚBLICA E GOVERNANÇA - EnAPG, 2004, Rio de Janeiro. Anais... Rio de Janeiro: ANPAD, 2004.

WORLD BANK INSTITUTE. A decade measuring of quality the of governance. Governance Matters 2006. Worldwide governance indicators. New Annual Indicators and Underlying data. Washington, DC, 2006.

Artigo recebido em: 12/09/2012

Aprovado em: 04/02/2013 